\title{
Living Theory Action Research: A Methodology for Improvement in Practice and Generation of Knowledge in Education
}

\author{
Bhawana Shrestha (https://orcid.org/ 0000-0002-5880-7603) \\ Kathmandu University School of Education
}

\section{ABSTRACT}

This paper will provide an overview of the philosophical premises, the generation of research questions, data collection and analysis process, potential ethical issues, and quality of inference of living theory action research methodology. Based on the ontological value that everyone has knowledge within themselves, living theory action research considers knowledge to be the creation from evaluation and reflection as part of actions to improve educational practices. This paper suggests a way to move ahead with living theory action research by shedding light on the significance of multimedia use and the role of educational influence in its methodology to communicate the meanings of expression of embodied values and for the validation process. This paper aims to help emerging educational action researchers understand living theory action research as an innovative methodology to address the gap between values and practical implementation for action researchers.

Keywords: educational influences, educational practices, living theory action research, methodology, philosophical premises, multi-media

\section{Living Theory Action Research: A Methodology for Improvement in Practice and Generation of Knowledge in Education}

The role of an educator's action is significant in breaking dominant practices and facilitating change through learning inside the classroom and beyond. An educator's action, according to Haley and Wesley-Nero (2002), includes their engagement in self-reflection, critical analysis of their own practices, construction of knowledge, and dialogic perspectives. Armstrong and Moore (2004) claim that action research helps educators bring about change through a conscious effort to raise awareness about democratic and social implications. Action research enables stakeholders to move toward reconsidering the role of academics and the role of academic institutions within community practice that can transform the pathway of the future of education. In this context, living theory, as a methodology, claims to have influence on everyone's lives and learning, either for better or for worse (Whitehead, 2018). Whitehead (2008) considers living theory as an explanation of an individual's educational influence in their own as well as other's learning and in the understanding of the social formation of the context where they live and work. Living theory action research establishes the relationship between the individual and the social context with the explicit use of action-reflection cycles in moving forward the inquiry that includes the expression of concerns if the values of the individual are lived fully in practice or not. Dewey (1933) explains this overall process as a reflective thinking process that includes a phase where the researcher comes out of doubt and hesitation through the act of searching and inquiring (as cited by Leitch \& Day, 2006). This paper will explore how this educational inquiry shifts from personal experiences to social orientation in living theory action research as a methodology that generates knowledge in education by 
focusing on its philosophical and methodological aspects.

\section{Philosophical Premises of Living Theory Action Research}

Living theory as a methodology was developed by Jack Whitehead to address the tension he discovered while conducting research between 1971-1972 for his master's degree in psychology of education. Whitehead (2008) determined that the disciplines of education were unable to incorporate the educational influences which equated to life experiences for both his, and others', learning. Dewey (1938) argued the importance of explaining life experiences in the disciplines of education is important for the improvement of the educators since understanding the experiential continuum of life leads to change and growth, reinforcing the individuals to develop the habitual ways of thinking to address new and different situations (as cited by Altan \& Lane, 2018). Whitehead (2008) stated that the process of inquiring about his own learning specifically in relation to his values led him to clarify the meanings of his values through practice. Whitehead (2019) argues that the educational influence in learning focuses attention on the idea that what is educational necessarily involves learning, but that learning, to be educational, must include values that carry hope for the flourishing of humanity. Durden-Myers and Whitehead (2019) describe the flourishing of humanity as the thriving of individuals encompassing the notion of wellness, ideally in happiness and life satisfaction, mental and physical health, meaning and purpose, character and virtue, and close social relationships. Thus, the contribution to humanity signifies the growth of practitionerresearchers studying their own learning and their educational influence to inform an educational theory. Foucault (2013) uses the term 'archaeology of knowledge' to suggest this process as the enunciative function that operates within the general excavation of consciousness and designates questions beyond what is already said. Thus, Foucault (2013) focuses on the importance of new measurements, guidelines, and rigor.

Living theory action research has been emerging as a popular discipline in response to the social science forms of action research
(Gearty \& Marshall, 2020). Any quality action research has both a disciplined process of intervention and a quality avenue to communicate the findings of the research (Hughes et al., 1998). The basic underlying philosophical difference between action research and living theory action research is in the ontological assumptions (Whitehead \& McNiff, 2006). While action research separates the position of the researcher and the researched by limiting the responsibility of the researcher to create the action plans to implement, living theory action research provides the researcher with the freedom to incorporate their values and find a common ground to negotiate between their desire to improve themselves with that of the others who wish to do the same (Gearty \& Marshall, 2020; Manfra, 2019). The integrity of living theory action research, which Marshall (2005) terms as "first-person action research," addresses the ability of the researchers to hold an inquiry into their own lives, explore their practices, and provide a point of reference and accountability as they periodically check back to their dialectical engagement. Polanyi and Sen (2009) explore this as the nature and implication of "tacit knowledge" and explain it as the valid knowledge of the problem, the researchers' ability to sense and pursue the solution, and the valid anticipation of the implication of the solution after the inquiry. The ontological value of the methodology is that everyone has a vast store of tacit knowledge within themselves, thus having the faith in their capacity to come to know the truth as their life-affirming energy through which they derive meaning and purpose for their lives (Polanyi, 1998).

The potential of living theory action research has been explored in a variety of forms in the field of education and is considered a major component of practitioner research (Mandell \& Herman, 2005; Whitehead, 2019). Schon (2008) terms this methodology as "reflective practice" where the practitioner acknowledges the tacit process of thinking in its "reflection- in action" process where the doing is accompanied by the researcher with constant interaction and modification on the ongoing practice in such a way that learning takes place. Dewey (1997) argues that not all experiences are equally educational nor independent of the 
desire or intent to have "every experience live on in further experiences" (p. 27).

Epistemology is that knowledge exists in different forms. Rather than regarding delivery of information as acceptable knowledge, it considers knowledge as the creation from the evaluation and reflection of our actions that allows us to imagine our future actions where we enact our values and draw insights from others' knowledge and values (Whitehead \& McNiff, 2006). The values in living theory are the commitment to promoting equality and democratic practices and to promoting inclusion and caring relationships (Whitehead, 2018). The researchers embody their ontological values which later transform as their epistemological standards of judgment, which will lead them to realize the need for the effective use of language and help them turn their research into an educational theory. llyenkov (1977) argues that "understanding falls into a state of logical contradiction (antinomy) here not only because, and even not so much because, experience is always unfinished, and not because a generalization justified for experience as a whole has been drawn based on partial experience" ( $p$. 34). Given that the profession of education requires a professional knowledge base, the living theory action research approach provides immense ground as well as respect for the educational researcher as an agent of educational improvement and change (McNiff \& Whitehead, 2009).

Standing on these philosophies, living theory action research attempts to address the contradiction that a researcher can hold certain educational values, while at the same time, deny them in practice. In that sense, its axiology, just like other action research, is that it acknowledges the emancipatory practices directed towards both the individual as well as collective empowerment. The practices are based on the initiation of research by the researchers' doubts and beliefs through their reflection, which gradually focuses more on the contradiction.

\section{Generating Research Questions for Living Theory Action Research}

Living theory action research involves self-study practitioner inquiry for transformation in an institution. Self-study practitioner inquiry is characterized by the inquiry of the roles of the self in the research project or the transformation of the institution through written reflections as well as critical conversations before, during, and after the action project (Kitchen \& Stephens, 2005). Gearty and Marshall (2020) argue that self-study practitioner inquiry is "first-person action research" where the inquirers are the aspiring change agents for the systemic practice who have the responsibilities to pay heed to what they are doing. Wood et al. (2007) argue that sustainable transformation is possible only at the micro-level if we question our own practices to ensure the representative value of the institution. The systemic inquiries of actionreflection cycles in living theory emerge from the practical research question, "How do I improve what I am doing?" (Whitehead, 2008, p. 107).

Thus, all research questions that stem from this insider view require emergent understanding throughout to ensure that the espoused values are supportive for the process of transformation. Hyslop-Margison and Sears (2016) argue that the need for generating research questions as meaningful democratic dialogue to foster critical thinking in the premise of current neo-liberal ideology that regards the primary purpose of education is only to help them find appropriate places in the labor market without considering moral and social discussion through the shift in perspective. Whitehead and McNiff (2006) differentiate the generation of research questions as different from other questions through the disruption of the epistemological hegemonies of the social sciences that are more performance-management oriented and through their focus on the quality of the work of the practitioners, specifically through rigorous peer and wider academic educational research community feedback. Research questions are thus generated based on the dialogic logic with the assumption that every statement is a response to a question that may be unspoken but is there in a tacit form, making it significant to ask the right kind of question which improves performance and perpetuates conversation (Gladwell, 2005).

The idea of living logic in living theory highlights its emergent property of the research questions. However, the research questions are formulated based on something that the educators experienced previously as the living 
contradiction, which Mezirow (1990) calls a "disorienting dilemma" (p. 14). It is a state when the educator holds two mutually exclusive opposites together in practice: one when they are practicing their educational values, and the other when they are denying the same values (llyenkov, 1977). The researchers trace their journey of growth to understand and improve the circumstances of the ones they hold responsibility for by exercising their methodological inventiveness and asking the research questions internally to oneself and discussing collectively with others and engaging in the process of transformation (Dadds \& Hart, 2002). The methodological inventiveness signifies working beyond action planning and assessing and integrating the content, context, and values of the researcher in the inquiry. The integration is meant to provide a descriptive, original representation of the search of the researcher's own understanding of an issue and their educational development. For example, the researcher will ask themselves, "How can I adapt my teaching to encourage students to prepare for class?" rather than asking "Why do the students not prepare for class?" (Wood et al., 2007, p. 69).

McNiff et al. (2009) claim that living theory action research is a distinctly human endeavor where individuals act with the best interest of others at heart "combining the ideas of taking purposeful action with educational intent and testing the validity of any claims we make about the process" (p. 18). According to Wood et al. (2007), possible examples of the research questions that enable us to reflect and interrogate our everyday practices and then ensure affirmative responses through critical continual reflection are:

- What do I do to improve my leadership skills to foster equality in my institution?

- Am I treating my teammates with humility and respect?

- How does my cultural background benefit/hamper my students when I am teaching?

- How can I encourage diverse perspectives in my classroom?

The two major objectives of quality research questions for action research, according to Whitehead (2008), are to: (1) help the researcher identify their potential, and (2) help the researcher acknowledge their flaws and limitations in terms of their theorizing and communication of their lived experiences.

\section{Data Collection and Analysis in Living Theory Action Research}

Data collection happens systematically throughout the process of practice. Embodied knowledge of practitioner-researchers is the primary data source in living theory where the researchers create and share the report of their educational influences to support and explain their ongoing cycles of research. Thus, data collection can be done through observation, interviews, tests, and surveys. Similarly, it can also include video/audio tapes, musical performances, transcripts of conversations, as well as other artwork. Whitehead et al. (2020) argue that the most important aspect of data collection is producing an evidence-based validated explanation for educational influence through a visual narrative.

\section{Multimedia Presentations Using Digital Technology}

Living theory methodology differs from other educational theories because it uses visual data to clarify the meaning of associated values and to enable empathic resonance. Blikstad-Balas (2016) argues that the use of video helps to dissect the complex and multifaceted phenomena into smaller entities which helps the researchers to look for patterns that are otherwise difficult to observe directly. Given that education is a value-laden practical activity, the personal knowledge of the researcher can be both powerful in expanding competence while also challenging. The challenge is not just to understand its limitations but also to communicate them. One of the challenges of communicating the meanings of embodied values in the data collection process of educational research is also related to the limitations of the words in print. Therefore, the need for the researcher to make video data accessible for the process of validation is a crucial step of the data collection process. Whitehead (2018) argues that "the use of digital data in living theory is different than that from a coding or category system" (p. 45), and highlights the significance of reflective writing in 
the contexts where there are problems of collecting video data because of physical or psychological challenges.

\section{Explanations of Educational Influences in Learning}

Living theory requires a researcher to collect data and produce concrete evidence to demonstrate that they have improved their practice as an educator through ostensive and lexical expression (McNiff \& Whitehead, 2009). Ostensive expression refers to the expression of the values and the principles that the researcher is associated with in their originality of mind and their critical judgment during their practice. Lexical expression refers to the meaning of words or values defined in terms of other words or values. Whitehead (2013) provides an example to clarify the significance of the use of both the ostensive expression and the lexical expression in the research by explaining how he would make his readers comprehend the solutions for the poverty in print-based academic text is. First he would focus on explaining ostensive expressions of meaning to show how the poverty in print-based academic texts can be overcome through digital narratives. Then, he would use lexical definitions to draw the readers' attention to academic texts to explore their implications for overcoming the poverty in printbased text. The idea of giving importance to both the ostensive and the lexical expression is to focus on the diversity and ecological complexity of the living spaces of the researcher to explain possible educational influences. Whitehead (2018) argues the importance of educational influences by connecting data with the educational responsibility. Polanyi (1998) claims educational influences as personal knowledge and trying to understand the world from both the individuals who acknowledge the importance of creative response and from the ones who resist it. The principle of action research in education is a value-laden practical activity that demonstrates the historical and socio-cultural influences associated with the continuous professional development of the researcher.

\section{Action Planning in Improving Practice and Generating Educational Knowledge \\ Action-reflection cycles are a transformational process "used to transform the}

embodied expressions of ontological values, in explanations of educational influences in learning, into publically communicable, epistemological standards of judgment" (Whitehead \& Huxtable, 2010, p. 7). Whitehead (2010) provides the following examples of reflective questions that researchers can answer individually or in a conversation with others as a part of the action planning process:

1. What do I want to improve? What is my concern? Why am I concerned?

2. What are the possible strategies for improvement and which one should I choose to act on my action plan?

3. What data will I collect to enable me to judge my educational influence in my professional context as I answer my question?

4. How should I evaluate the influence of the actions in terms of values and understandings?

5. How should I modify my concerns, ideas, and actions in the light of evaluations?

6. What should I condsider while making public a validated explanation of educational influences?

The action planning process of living theory overlaps and connects with adult learning theories like transformative learning theory and critical theory. Similar to the framework of living theory, practitioner-researchers employ a dialectic approach for finding solutions to concerns (Wang et al., 2019). They further argue that we are all surrounded by developmental tasks and life problems and different personal as well as institutional ideologies necessary to critically reflect on living theory's idea of "living contradiction." Mezirow (1990) emphasizes transformative learning through service-learning projects and reflective practice similar to the action-reflection cycle by focusing on the re-assessment of the assumptions that one gains over their developmental years.

The key actions for preparing a project, according to McNiff (2008), are classified into a set of phases: planning, designing, doing, evaluating, explaining, modifying, and communicating. The planning phase involves finding the issue to investigate, which is then refined in the designing phase where the researcher brings in research participants, critical 
friends, validation groups, and identifies resources, timeline, ethics, as well as feasibility. In the doing phase, relevant data is collected while emphasizing the monitoring action, leading to the evaluation phase where the researcher focuses on the quality of the generated evidence of the data. Then, in the explanation phase and the modifying phase, the significance of the action is explained in terms of the educational influences in learning, and new ideas for action are developed, respectively. Finally, in the communicating phase, the planning for the multimedia representation is done to ensure the quality of the project. The generation of knowledge continues throughout the process where the researchers are thinking actively and critically reflecting while asking for feedback from their colleagues and supervisors for systematic ongoing reflection. The generated knowledge goes through critical scrutiny of others to ensure its rigor and validity.

\section{Potential Ethical Issues in Living Theory Action Research}

Action research findings can shift from its emancipatory purposes if the researcher is not morally and ethically aware about the social, political and economic conditions of educational practices (Van Manen, 1990). Apart from that, prior ethical considerations avoid the risk of harming both the participants and the researchers and minimizes the risks of leaving negative legacies. It also helps the researchers demonstrate respect for the participants by being conscious about protecting intellectual freedom by understanding that an individual has the capacity for originality and critical engagement (McNiff \& Whitehead, 2005). Intellectual freedom protects the voices of diverse communities and helps foster interpersonal relationships, empathy, and respect. Moral and ethical considerations should be a priority right from the planning stage and should be documented properly.

Whitehead and McNiff (2006) provided three basic categories for an ethical framework in living theory action research: access, safeguarding rights, and assuring good faith. This involves obtaining both the oral and written permission of participants and safeguarding their rights of voluntary withdrawal from the research process at any time if they wish to while assuring their confidentiality. Because the nature of educational research asks both the researcher and the participants to expolore sensitive topics, like reflecting on educational influences and values, it is important to negotiate access and make the publication and distribution limited if needed. Thus, it is always important to contact all the participants and secure their permission prior to publication.

Meanwhile, owing to the importance of visual data in living theory action research, the researcher must be specifically conscious regarding the potential ethical problems that might arise if they did not obtain permission for making parts of a video public. Similary, Brandenburg and Gervasoni (2012) highlight how dealing with sensitive issues and reporting them mindfully demonstrates trust in the self as well in the practitioner-researchers throughout the process. The ongoing need for critical appraisal extends beyond the associated institutions and ethical standards and goes much farther than commonly accepted criteria. Ernest (2012) provides a framework for ethical consideration which asks the researchers to critically reflect on the outcome of the presentation and publication in public forums and to observe how the researchers' assumptions and beliefs have been challenged, supported, or altered throughout their practice.

\section{Quality of Inference}

Validity in action research involves multiple people, techniques, and processes, thus including personal validation, social validation, and public legitimation (McNiff \& Whitehead, 2009). When it comes to validation, it is important to consider the nature of knowledge, the embodied values, the methodology used in educational research, educational influences and the logic of educational inquiry. The nature of living theory action research is characterized by the inclusion of "l" as a living contradiction and is, therefore, associated with the self-study of teacher education practices (S-STEP). Whitehead (1972) argues that the researcher should perpetually ask questions related to the validation of the knowledge that they are claiming.

Campbell (2013) has used empathetic resonance to communicate the meaning of the 
researchers' ontological values of "being loved into learning" in their explanations of educational influence. The use of visual data, therefore, is considered an important measure to look into validity and ethical consideration as it focuses on the significance of the relational dynamic awareness to comprehend the relationship between the researcher and participants. Living theory action research focuses more on the educational influences of the researcher and keeps the researcher at the center by focusing on their improvement of practice. Whitehead (2008) emphasized the importance of the validation groups as an important aspect of validation for the self-study practitionerresearcher. Hebarmas (1976), as cited in Niemi (2005), claims that the connection between understanding and reason normally consists of moral righteousness, reasons, belief that the action is the right thing to do, and the demand of the context. The validation groups consist of between three to eight peers and use four questions derived from the four criteria of social validity provided by Habermas (1976) on comprehensibility, rightness, truthfulness, and authenticity (as cited in Whitehead, 2008).

\section{Conclusion}

This paper highlighted the methodological and philosophical premises of living theory action research that is based on the professional practice question, "How do I improve what I am doing?" Living theory action research is based on the living logic of educational inquiry and embodied values of the researcher to promote quality-based practice in education, and it is important to make the findings public for the contribution of improving educational practices. The paper also provided considerations for attempting living theory action research by explaining its data collection and analysis process, potential ethical issues, and quality of inference. Finally, this paper shed light on the significance of the use of multimedia in action research to communicate the meanings of expression of embodied values in educational practices. Overall, the paper emphasized the use of living theory action research for the extension and transformation of the educational practices by helping the researchers generate their living theory through the systemic use of reflective data, multimedia data, as well as the validation group.

\section{References}

Altan, S., \& Lane, J. F. (2018). Teachers' narratives: A source for exploring the influences of teachers' significant life experiences on their dispositions and teaching practices. Teaching and Teacher Education, 74, 238-248. https://doi.org/10.1016/j.tate.2018.05.0 $\underline{12}$

Armstrong, F., \& Moore, M. (2004). Action research: Developing inclusive practice and transforming cultures. In Action research for inclusive education: Changing places, changing practice, changing minds ( $\mathrm{pp} 1-17$ ). Psychology Press.

Bigger, S. (2021). What is the potential educational influence of the educational journal of living theories (EJOLTs)? Explorations in methodology and theory. Educational Journal of Living Theories, 14(1), 68-85.

Blikstad-Balas, M. (2016). Key challenges of using video when investigating social practices in education: Contextualization, magnification, and representation. International Journal of Research \& Method in Education, 40(5), 511-523. https://doi.org/10.1080/1743727x.2016 .1181162

Brandenburg, R., \& Gervasoni, A. (2012). Rattling the cage: Moving beyond ethical standards to ethical praxis in self-study research. Studying Teacher Education, 8(2), 183-191. https://doi.org/10.1080/17425964.2012 .692991

Campbell, K. H. (2013). A call to action why we need more practitioner research: $A$ response to a teacher educator uses action research to develop culturally conscious curriculum planners. Democracy and Education, 21(2), 1-8. https://democracyeducationjournal.org/hom e/vol21/iss2/7

Dadds, M., \& Hart, S. (2002). Doing practitioner research differently. Routledge.

Dewey, J. (1997). Experience and education. Free Press.

Durden-Myers, E., \& Whitehead, M. (2019). Human flourishing and physical literacy. 
In Physical literacy across the world (pp. 308311). Routledge.

Ernest, P. (2012). What is our first philosophy in mathematics education? For the Learning of Mathematics, 32(3), 8-14.

Foucault, M. (2013). The archaeology of knowledge (2nd ed.). Routledge; Taylor and Francis.

Gearty, M. R., \& Marshall, J. (2020). Living life as inquiry - A systemic practice for change agents. Systemic Practice and Action Research, 34(4), 441-462. https://doi.org/10.1007/s11213-02009539-4

Gladwell, M. (2005). Blink: The power of thinking without thinking (1st ed.). Penguin.

Haley, M., \& Wesley-Nero, S. (2002, March). Dialogic construction and reflective practice: A teacher educator's action research study of teacher as learner [Paper presentation]. TexFlec Conference, Austin.

Hyslop-Margison, E. J., \& Sears, A. M. (2016, August 5). The Neo-liberal assault on democratic learning. ResearchGate. https://www.researchga te.net/publication/268427492 The NeoLiberal Assault on Democratic Learningllyenk ov, E. V. (1977). Dialectical logic: Essays on its history and theory

Kitchen, J., \& Stephens, D. (2005). Self-study in action research: Two teacher educators review their project and practice. Ontario Action Researcher, 8(1), 1-5.

Leitch, R., \& Day, C. (2006). Action research and reflective practice: Towards a holistic view. Educational Action Research, 8(1), 179-193. https://doi.org/10.1080/096507900002 $\underline{00108}$

Mandell, A., \& Herman, L. (2009). Mentoring: When learners make the learning. In Transformative learning in practice: Insights form community, workplace, and higher education (pp. 78-88). Jossey-Bass.

Manfra, M. M. (2019). Action research and systematic, intentional change in teaching practice. Review of Research in Education, 43(1),
163-196. https://doi.org/10.3102/0091732x1882 1132

McNiff, J. (2008, September 12). Planning, designing and doing action research. Action Research.

https://www.actionresearch.net/writings/jack/jmpl anar.pdf

McNiff, J., \& Whitehead, J. (2005). All you need to know about action research (2nd ed.). SAGE Publications.

McNiff, J., \& Whitehead, J. (2009). Doing and writing action research. Sage Publication Ltd. Mezirow, J. (1990). How critical reflection triggers transformative learning. In Fostering critical reflection in adulthood: $A$ guide to transformative and emancipatory learning (1st ed., pp. 1-20). Jossey-Bass.

Niemi, J. I. (2005). Habermas and validity claims. International Journal of Philosophical Studies, 13(2), 227-

244. https://doi.org/10.1080/0967255050008046 $\underline{2}$

Polanyi, M. (1998). Personal knowledge:

Towards a post-critical philosophy. Psychology Press.

Polanyi, M., \& Sen, A. (2009). The tacit dimension (2nd ed.). University of Chicago Press.

Schon, D. A. (2008). The reflective practitioner: How professionals think in action. Basic Books.

Van Manen, M. (1990). Beyond assumptions: Shifting the limits of action research. Theory Into Practice, 29(3), 152-

157. https://doi.org/10.1080/0040584900954344 $\underline{8}$

Wang, V. X., Torrisi-Steele, G., \&

Hansman, C. A. (2019). Critical theory and transformative learning: Some insights. Journal of Adult and Continuing Education, 25(2), 234-251. https://doi.org/10.1177/147797141985 $\underline{0837}$

Whitehead, J. (1972). A preliminary investigation of the process through which adolescents acquire scientific understanding [Unpublished master's thesis]. University of London. 
Whitehead, J. (2008). Using a living theory methodology in improving practice and generating educational knowledge in living theories. Educational Journal of Living Theories, 1(1), 103-126.

Whitehead, J. (2013, September). Researching to overcome poverty with action research and living educational theories [Paper presentation]. Symposium on Creating Educational Theories which Engage with Issues of Poverty at the British Educational Research Association Conference, University of Sussex.

Whitehead, J. (2018). Living theory research as a way of life. Brown Dog Books.

Whitehead, J. (2019). Action research for selfstudy and living educational theories. In Action learning and action research: genres and approaches (pp. 97-110). Emerald Publishing.

Whitehead, J., Delong, J., Huxtable, M., Campbell, L., Griffin, C., \& Mounter, J. (2020). Self-study in elementary and secondary teaching: A living theory approach. In 2nd International handbook of self-study of teaching and teacher education practices (pp. 1-33). Rotterdam.

Whitehead, J., \& McNiff, J. (2006). Action research: Living theory. Pine Forge Press. Whitehead, J., \& Huxtable, M. (2010, September). How are we sustaining educational relationships to improve educational practices with teachers and pupils in the generation of educational knowledge? [Paper presentation]. British Educational Research Association Annual Conference, University of Warwick.

Wood, L. A., Morar, T., \& Mostert, L. (2007). From rhetoric to reality: The role of living theory action research in transforming education. Education as Change, 11(2), 67-80. https://doi.org/10.1080/16823200709487 166

Zuber-Skerritt, 0. (2001). Action learning and action research: Paradigm, praxis and programs. In Effective change management through action research and action learning: Concepts, perspectives, processes and applications (pp. 1-20). Southern Cross University Press. 